\title{
Consolidation of a collar truss with a steel cable system
}

\author{
Giacomo Crivellari, a , Jorge M. Branco ${ }^{1, b}$ \\ ${ }^{1}$ ISISE - Dept. Civil Engineering, University of Minho \\ Azurém, 4800-058 Guimarães, Portugal \\ a crivellari.giacomo@gmail.com, ${ }^{b}$ jbranco@civil.uminho.pt
}

Keywords: Timber truss, consolidation, post-tensioning

\begin{abstract}
Post-tensioning techniques for strengthening existing timber elements have been used throughout history with excellent results. Former applications on wooden trusses have already shown some of the advantages of such a consolidating system, but very few tests were performed on the topic. During an experimental campaign, a full-scale historical timber truss was deeply analysed and tested in its original (unreinforced) condition, reaching a considerable level of damage. It was later repaired with a steel cable system, using prestresses to recover the structure bearing capacity, and tested again. The results show that the repair allowed a recovery of at least the $80 \%$ of the ultimate load-carrying capacity. The complete failure was not achieved, but it is likely to be presumed that the structure could have regained the totality of its strength. The data acquired in both tests were later compared in order to understand in detail the behavior of the truss.
\end{abstract}

\section{Introduction}

Timber structures have been built since ages and are worldwide spread. Between all the historical realizations, timber trusses are an outstanding combination of aesthetic, functionality and structural optimization of each load-carrying member. Many different layouts were generated according to the particular conditions, but nowadays all of them share the necessity to be preserved and, in the worse cases, to be consolidated, for guaranteeing their conservation.

Many retrofitting techniques have been developed, and lots of them have been systematically reported in dedicated manuals. However, while some applications were largely used and taught, others have been slowly left aside, with the risk of forgetting them and losing part of the technical and constructive heritage. For instance, the retrofitting of historical timber elements with prestressed system has been performed several times in the past, but still there are many unknowns that discourage new applications and limit its development. The post-tensioning of steel elements, as a specific way of applying the prestresses, has been proposed since the beginning of the $19^{\text {th }}$ century [1], and it has been applied both for new construction and for restoration. Some inspiring cases, realized on historical timber trusses by some Italian conservators, have already shown the potential of this strengthening method, as the roof structure of theatre of Sarteano [2], or the one of Savona [3].

In order to compensate the lack of knowledge on post-tensioning methods for retrofitting timber structures, an experimental campaign has been carried out by the authors. A full-scale collar truss has been saved during the dismantling of an historical factory, and it has undertaken several tests to be fully characterized and prepared for the application of a prestressed steel cable system. The twofold purpose of the campaign focused on the realization of the retrofitting and on the comprehension of its behavior while interacting with the timber structure. 


\section{Preliminary studies}

Geometry assessment. While still unmounted, the truss has been carefully studied with different approaches. At first, all the composing elements have been renamed following the pattern chosen during the dismantling process (Fig. 1). Furthermore, every piece has been discretized in segments $40 \mathrm{~cm}$ long, and all sections have been analysed with different non destructive tests. The first step was the geometrical survey of the structure, and the relative differences in the gross cross section ends, have been accurately measured. A part from some local reductions in the cross sections, due to the nature of the material or to the carpentry joints, the timber elements presented a regular shape, with mean values of $195 \times 230 \mathrm{~mm}^{2}$. The detailed measures are reported below (Table 1).

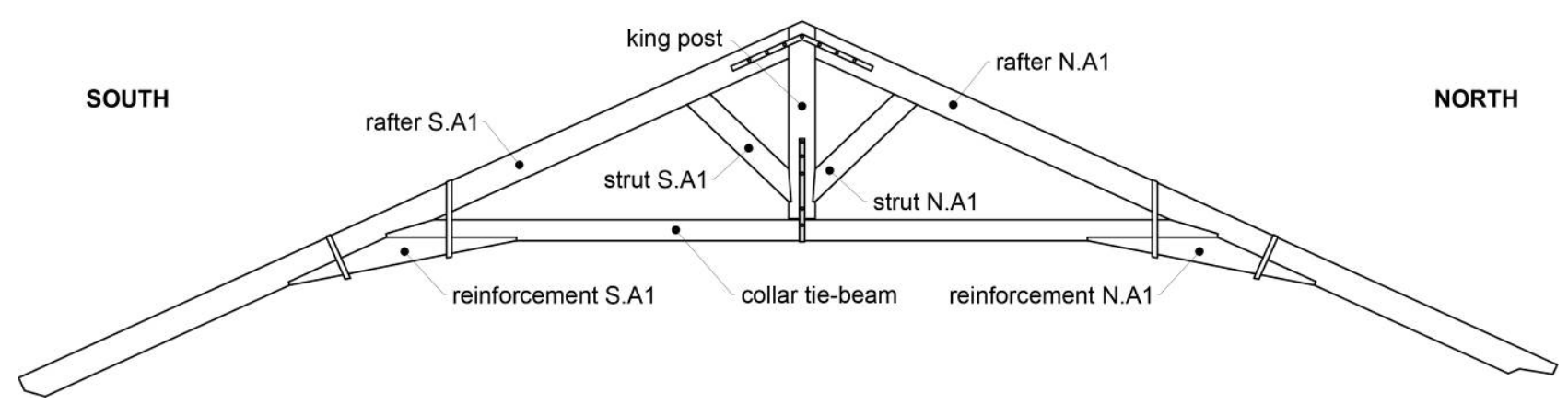

Fig. 1 - Scheme of the collar truss analysed

Table 1 - Measures of the elements composing the collar-beam truss.

\begin{tabular}{cccccc}
\hline Dimension $[\mathrm{mm}]$ & Rafters & Tie beam & Struts & King post & Reinforcements \\
\hline base & 8000 & 7650 & 1220 & 1950 & $2230(\max )$ \\
\hline height & 235 & 205 & 230 & 270 & $280(\max )$ \\
\hline lenght & 195 & 190 & 205 & 205 & 200 \\
\hline
\end{tabular}

Decay visual mapping. A second step consisted in the identification of the damages present on the truss and their mapping. It was observed that fungi and xylophagus insects affected the wood (Fig. 2). The most deteriorated part was the area closest to the supports, as typically happens in wooden structures embedded in walls. The graphical restitution of the decay was overlapped with the data offered by the consecutive tests, to obtain a crosschecking of the results.
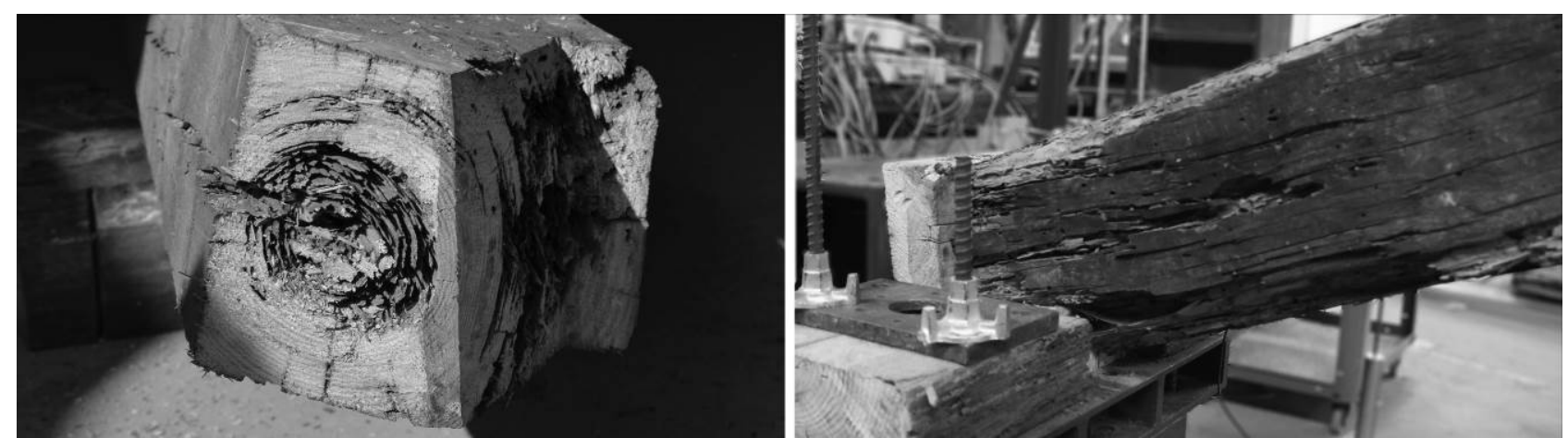

Fig. 2 - Decays affecting the truss in the South support (left) and in the North one (right)

Non Destructive Tests. To have a qualitative idea of the decay distribution and depth, a springloaded penetrometer was used on every surface, testing every section in twenty-four different spots. Considering that tests depth was maximum $40 \mathrm{~mm}$, the results were just related to the surface state. A further test was done by using a Resistograph ${ }^{\circledR}$, checking every segment in five different locations, both on the bigger and smaller dimensions. This technique allows to spot inner voids or deep decaying phenomena, but in this particular case, no major defects were found in the central 
part of the elements. An ultimate test, the ultra-sound method, was used to assess the decay different levels between various parts of the same elements, but the fissures present in the timber affected considerably the results.

Bending test. Following the requirements of the EN 408:2003 [4], bending tests were performed on spare pieces belonging to a similar truss. During the dismantling of the original roof structure, some other elements were saved, that have been then tested and which results have been compared to the truss under analysis. One rafter and two tie beams became the specimens for the bending test, on which a total of 18 experiments were done, considering both the local and the global behavior of the elements. The outcomes were the estimation of the Modulus of Elasticity (MoE) and of the density, which have been later compared (Table 2) with the national Portuguese codes [5] and another study, specific on the wood specie used in this case, the Pinus pinaster [6]. The differences in the values should be correlated with the historical and partially decayed character of the analysed structure, which has been assessed being older than 100 years.

The density evaluation has been done using a weight, calculating the ratio with the apparent volumes of the specimens. Considering the absence of major inner voids, and the limited level of decay of the elements, is possible to claim that the density results were acceptably close to the real ones.

Table 2 - Characteristics for the Pinus pinaster, according to different references.

\begin{tabular}{cccc}
\hline & Bending strength $\mathrm{f}_{\mathrm{m}}[\mathrm{MPa}]$ & MoE $[\mathrm{GPa}]$ & Density $\left[\mathrm{kg} / \mathrm{m}^{3}\right]$ \\
\hline Bending tests & $49.0-63.0$ & $10.9-13.6$ & $556-593$ \\
\hline LNEC [5] & $18-35$ & $12-14$ & $580-610$ \\
\hline Other [6] & $49.9-62.3$ & $12.3-14.0$ & $560-589$ \\
\hline
\end{tabular}

\section{Assemblage and test set-up}

The truss has been then remounted, assuming the configuration of its original location. Thanks to the expertise of an experienced carpenter, it was possible to assemble the elements with few, minor modifications, using all the elements in the correct positions, and interlocking them with the original joints. The metal bands that were tightening together the most delicate connections had to be replaced by new ones. The steel plates have been realized according to the original design, trying to replicate the same effects on the structure. The old wrought iron nails have also been changes in favor of steel screws, keeping into account the resisting sections of both old and new elements, with no alteration in the stiffness of the connections. To avoid a certain localized rupture in the support, the most decayed parts of the rafters were removed, cutting them respectively about $20 \mathrm{~cm}$ on the North side, and $40 \mathrm{~cm}$ in the southern one.

For the set-up of the laboratory facilities, few preliminary test were previously performed, in the framework of an international workshop [7]. In fact, a part from the truss here studied, another similar one was successfully reassembled and tested, allowing a proper preparation for the experimental configuration. The testing layout finally chosen is shown in Fig. 3 below.

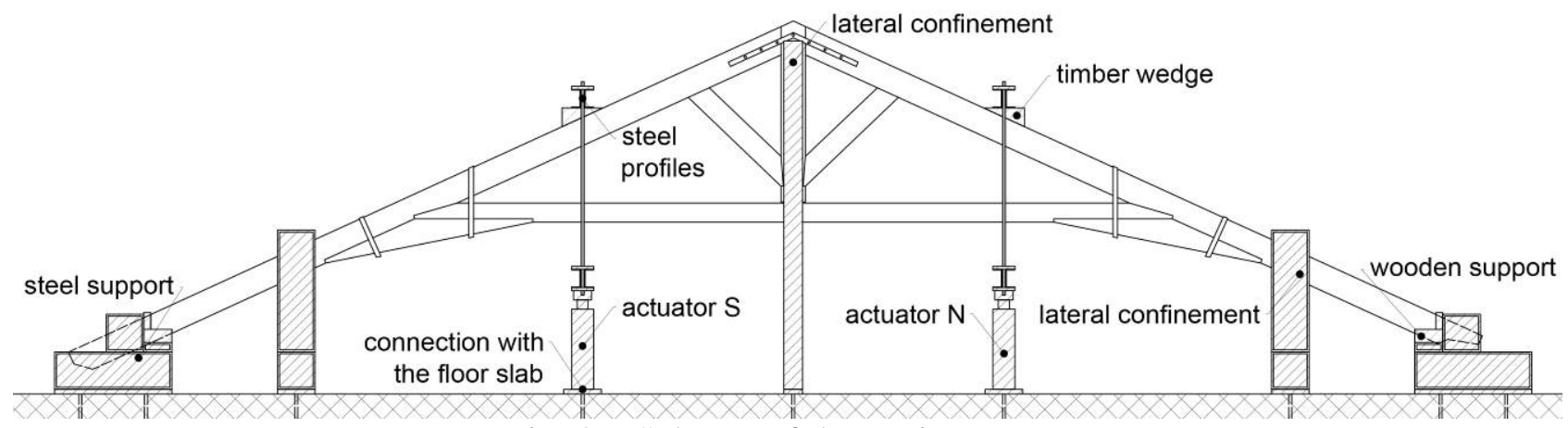

Fig. 3 - Scheme of the testing set-up 
As it possible to appreciate from the scheme, the experiments have been carried out with specific boundary conditions reflecting some particular assumptions that have been previously made. Firstly, the supports did not allow any major horizontal displacement, resembling a double-hinged configuration. Two wooden supports were interposed between the rafter and the steel elements, as sacrificial elements that could have permitted some small adjustments. Although the resemblance of the original configuration could have suggested a different supporting system (as masonry walls deform, and so allow horizontal displacement), to guarantee safe and controlled experiments this set-up have been preferred. Moreover, as the aim of the tests was to focus on in plane behavior of the timber structure, some lateral confinements have been placed, coupling them on both sides of the truss, in order to keep it vertical while loading it. Three couples of confinements have been place, one in the middle, and two bracing the rafters.

The loading system consisted in two hydraulic actuators, firmly anchored to the concrete floor slab of the laboratory, that were connected to the timber structure through a system of steel sections. The load was imposed in the upper part of the truss rafters, exactly in the middle point between the strut connection and the tie beam joint. The actuators were pulling down the steel over-structure, and consequently, loading the truss. The devices were displacement-controlled, allowing to set a constant loading speed, and were capable of developing a maximum force of $500 \mathrm{kN}$, within a displacement range of $150 \mathrm{~mm}$. Although such high values of force were never reached, it was instead necessary to use the totality of the displacement range.

\section{First test}

The timber truss, completely assembled and placed in the testing set-up, has been equipped with a full set of LVDTs, which were distributed all around the structure, and located in the most meaningful positions. The loading speed was set to $0,05 \mathrm{~mm} / \mathrm{s}$ and the structure was initially stressed with a preload of $20 \mathrm{kN}$. With this initial force, the truss adjusted all the gaps and irregularities deriving from the reassembling. After this initial input, the set-up was retightened and the first test was performed. It took in total 50 minutes, with a maximum displacement equal to $150 \mathrm{~mm}$ in the actuators. The actuators induced in the truss, a maximum force of $269 \mathrm{kN}$, divided in $142,5 \mathrm{kN}$ for the North jack, and 126,5 kN in the southern one.

The structure was heavily damaged, with visible fissures in the rafters, located just below the loading points, and in correspondence with the strut - rafter connection (Fig. 4). Many minor cracks appeared all around the truss, and the tie beam joints were significantly opened during the test. The wooden support, separating the rafters from the steel bases, startied to crush under the compression stresses. The overall structure showed a tendency of deforming in the out-of-plane direction, with a torsion around the tie beam that affected mainly the upper part of the truss. The deformation is shown in Fig. 5 below. After the test, this latter damage was almost completely reabsorbed by the structure.
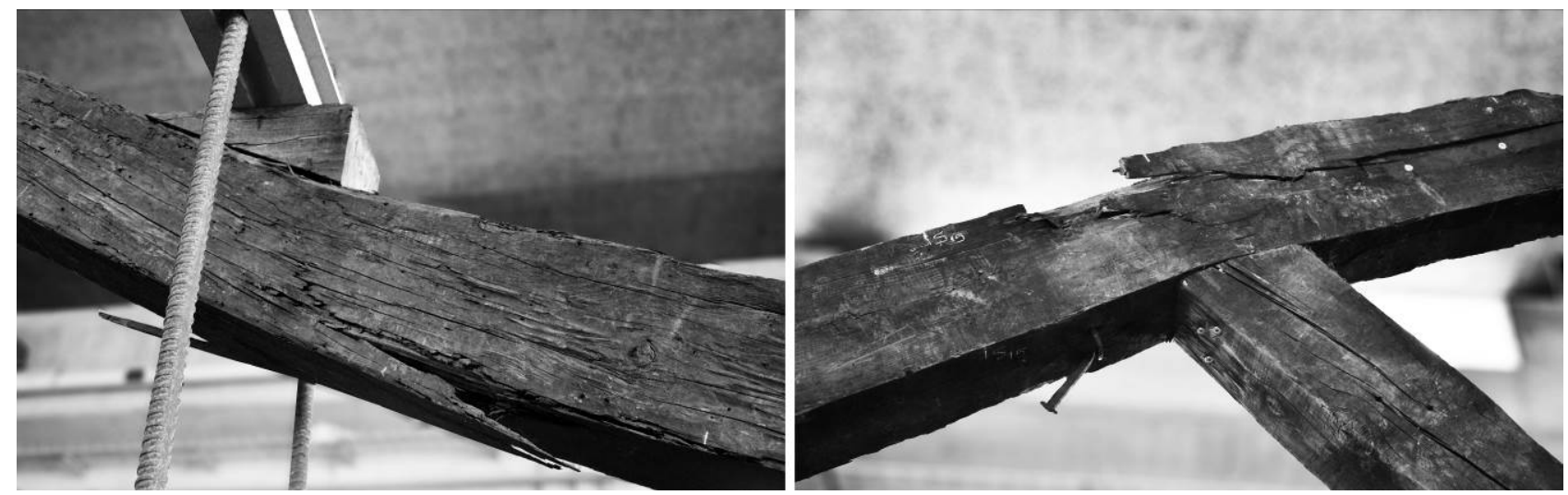

Fig. 4 - Fissures in the South rafter in the bottom part (left), and in the strut - rafter joint (right). 


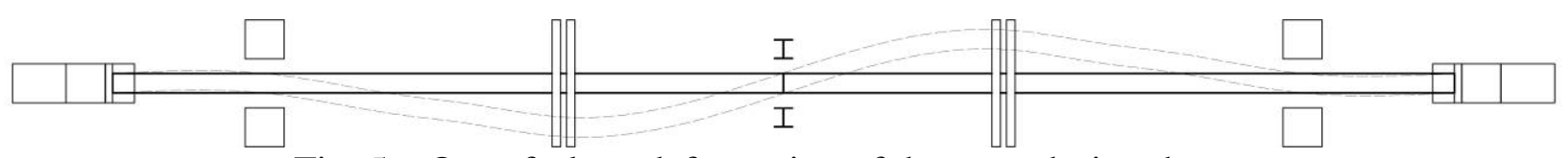

Fig. 5 - Out-of-plane deformation of the truss during the test

\section{Retrofitting system}

After the un-loading of the truss, it was possible to start the repairing operations. Firstly, the cracks over the struts were closed using $500 \mathrm{~mm}$, fully threaded, inox screws. Secondly, the rafters were lifted with the help of a crane, and straightened again. At the same time, the post-tensioned retrofitting system was conceived. It was designed to counteract the bending stresses that was harming the most the structure, and in the meantime transform the imposed load in stresses that could be better borne by the timber elements (see Fig. 6). Some references were found in the state of the art by former realization of other authors [8], but the specific conditions imposed an original design. The basic requirements of the intervention were the light approach to the existing elements, a rapid execution with limited budget, and the feasibility of such a technique with real case boundaries (i.e. impossibility to operate from the top for the presence of a roof cover). A fundamental criterion was also the control of the applied prestress. More restriction were imposed by the many obstacles of the set-up and testing system. It was in fact impossible to operate anywhere below the line of the tie beam, considering the presence of all the laboratory devices.

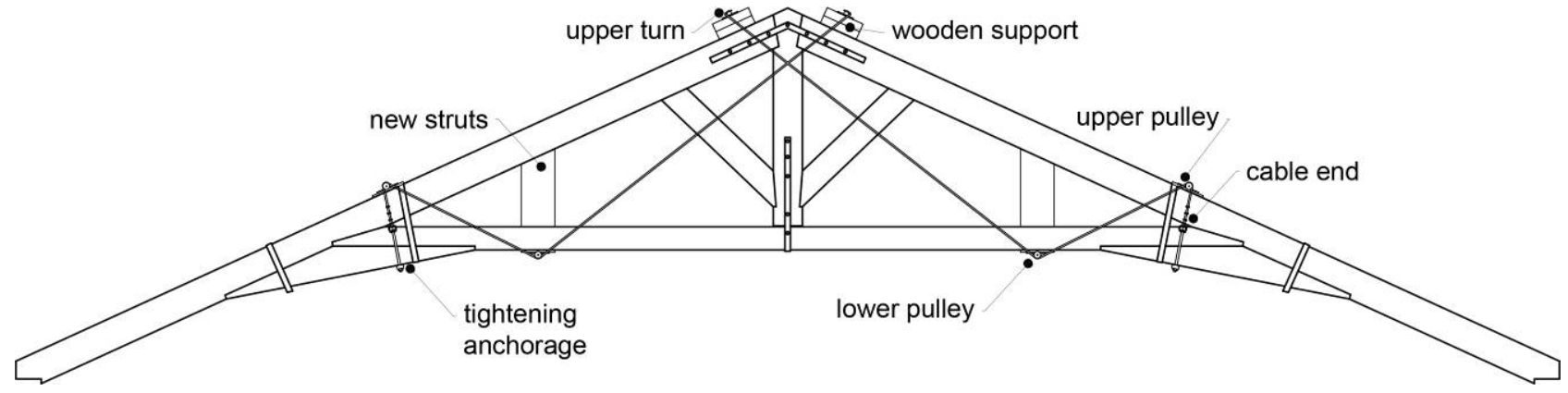

Fig. 6 - Retrofitting intervention

The cable system was twice symmetrical, both to the vertical and longitudinal axis. In fact, all the retrofitting was done with two cables, made with galvanized steel, $14 \mathrm{~mm}$ diameter, 6x19 WSC, with ultimate strength of $139 \mathrm{kN}$. Each line was starting from the tightening anchorage, and after some directional changes at the upper and lower pulleys, it was directed on the other side of the truss passing around the upper turn (see Fig. 7). This imply that the retrofitting system was simply laid on the truss, and very few screws were put to fix the elements, making the intervention almost totally reversible. Between the new additions and the historical structure, some wooden sacrificial elements were interposed. All the metal pieces were realized following this specific design, but an accurate choice of commercial sections allowed a drastic reduction of costs and production time.

The prestresses were induced in the structure through the anchoring pieces. Each cable end was tied to a steel ring, connected to a metal threated rod. These, were firmly kept in position by steel nuts, pushing against a massive metal bar in contact with the truss. While tightening the nuts, the rods were pulling the cables, inducing the necessary tension. With a dynamometric key was possible to evaluate the torsion applied to the system, and with it calculating the axial force in the cables. The post-tensioning was done progressively and as uniformly between the four application points. In total, a prestress of $29 \mathrm{kN}$ was applied in the retrofitting system.

Moreover, new struts were placed just below the loading point, to redistribute the stresses through the whole timber structure. As would be possible to appreciate in the results section, the cable system induced multiples benefic actions on the truss. A part from the main purpose, the counteraction of the loading stresses, the cables helped to tight both the rafters - king post connection, and the tie beam - rafter ones. 

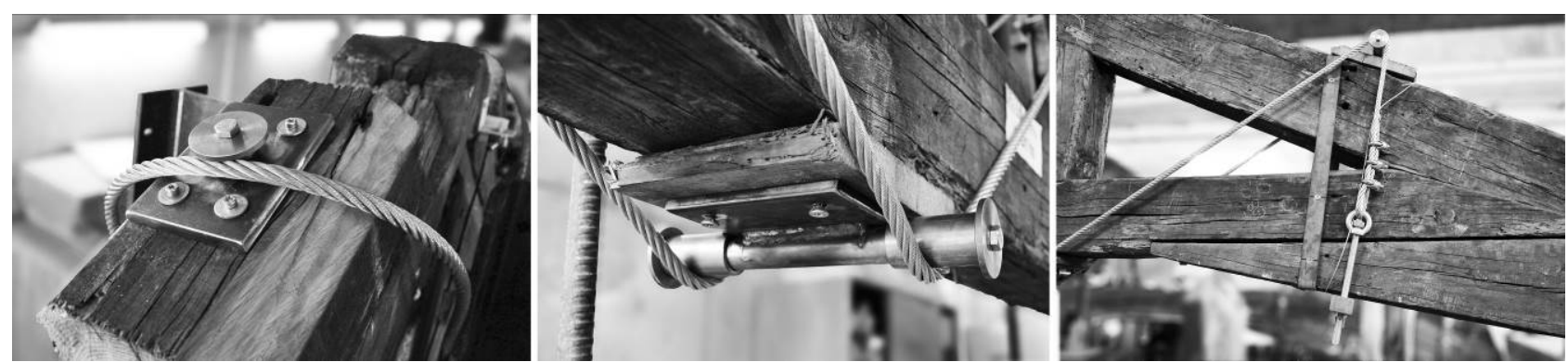

Fig. 7 - Details of the retrofitting. Upper turn (left), lower pulley (middle) and anchoring (right).

\section{Second test and results comparison}

Following the same loading pattern of the first experiment, the truss was preloaded with $20 \mathrm{kN}$, to check the right interlocking of all the elements. Then the real test started, and was imposed again a constant loading speed of $0,05 \mathrm{~mm} / \mathrm{s}$, taking 43 minutes before being stopped. Due to safety reasons, it was not feasible to reach again the rupture of the structure. In fact, the out-of-plane deformation was too significant to assume that the truss would not have failed under a torsional effect, with consequent problems in the testing devices, laboratory facilities and for the personnel involved. However, thanks to the data recording system, good results were collected and analysed.

During the second test a maximum load of $220 \mathrm{kN}$ was reached, divided between $108 \mathrm{kN}$ on the South actuator and $112 \mathrm{kN}$ in the North one. The estimation of the goodness of the repairing in terms of load-carrying capacity shows that the structure regained the $82 \%$ of its strength, which is a remarkable achievement if compared to the residual state after the first test. It was also noticeable the change in the structural behavior, change that was highlighted from the outputs form the LVDTs set-up (see Fig. 8). Are here presented some significant ones, in order to explain these modifications. The information gathered during the first test are represented through dashed lines, and the second test is drawn with continuous ones. On the horizontal axis are shown the deformation registered by the transducers, expressed in millimeters, while on the vertical direction is shown the total load applied in that moment, in $\mathrm{kN}$.

The data presented have been selected between all the outcomes deriving from both the first and the second test. These information have been qualitatively interpreted to better understand the behavior of the truss during the two experiments. Although the structure was slightly asymmetrical, both in geometry and in the displacement response, the differences were so small to become negligible for the overall comprehension of the tests. The asymmetry is understandable from the graph $L V D T 8$, which shown how the middle point in the tie beam was shifting from one side of the other of the central vertical confinement. The graph ACT 824 refers to the inner controller of the actuator. During the first test, an abrupt rupture happened, generating the drop after the linear behavior. In the second test, the failure was not achieved, but the graphs shows how the upper rafter was moving more under the same loading. At the same time, the lower part of the structure was also moving faster, as displayed in graph $L V D T 5$. This represents a uniform movement of the whole upper part of the truss, implying an improvement of the stiffness in this area. From LVDT 13 and 14 is understandable the change in the reactions at the support level. The horizontal thrust was much bigger after the retrofitting, when compared to the first test, and contemporaneously the rafter was rotating more. These modifications imply a less ductile behavior of the upper part of the truss, which consequently loaded more the supports. Eventually, the graph LVDT 7 is showing the effectiveness of the steel cable system in the confinement of the carpentry joints. The sensor has been placed in the upper part of the connection, and while during the first test there was almost no change in its dimension, in the second experiment is was considerably under the compression effect, generated by the post-tensioning. 


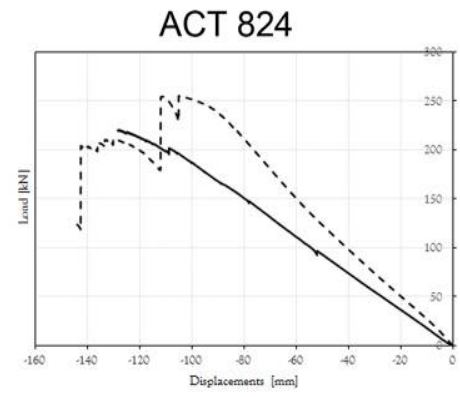

LVDT 7

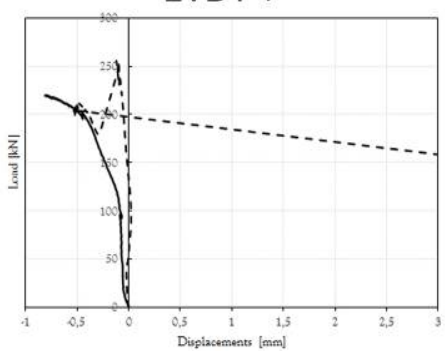

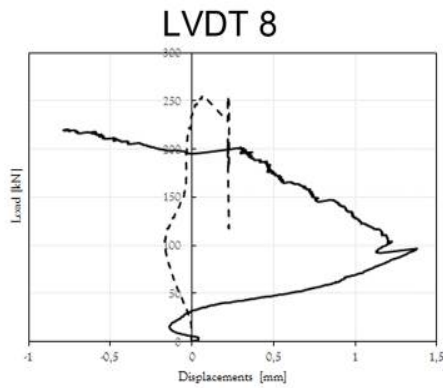

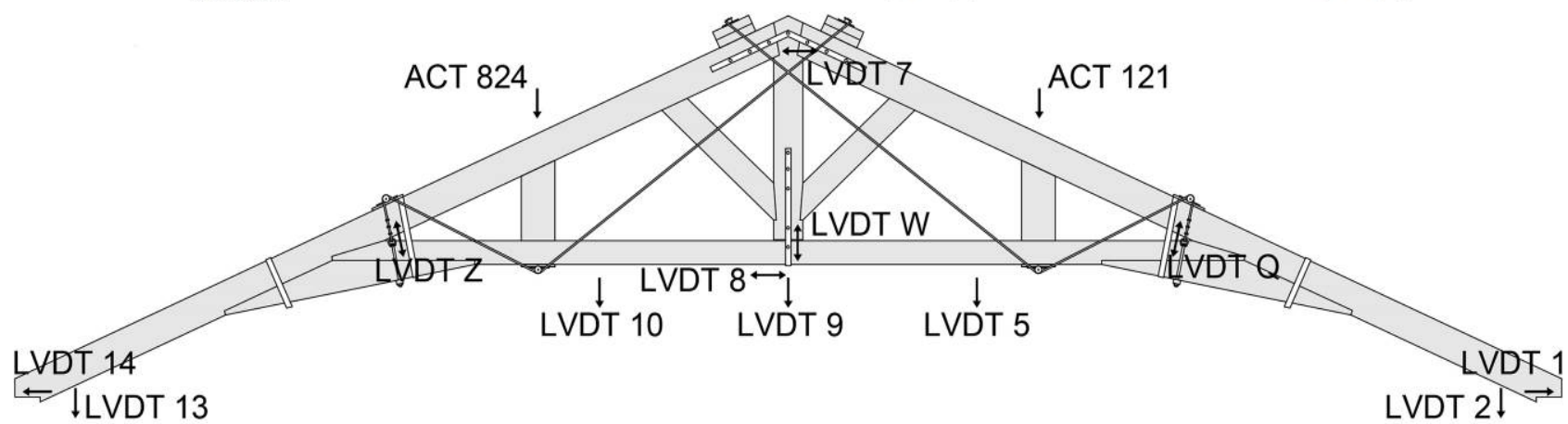

LVDT 14

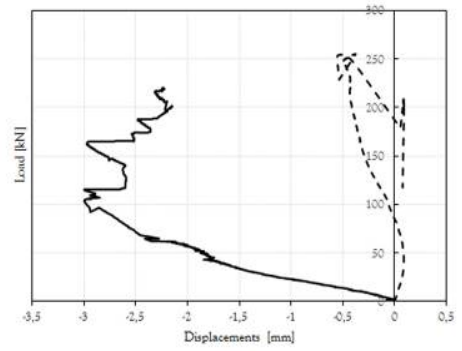

LVDT 13

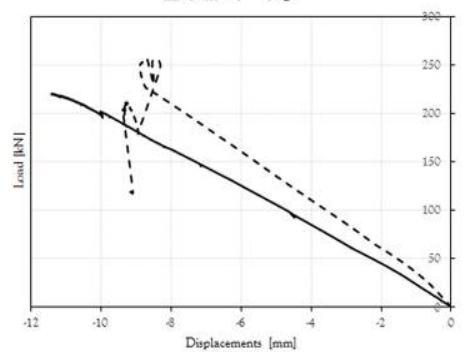

LVDT 5

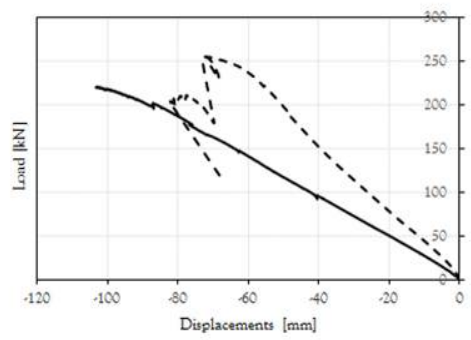

Fig. 8 - LVDTs disposition and result comparisons between first (dashed) and second (continuous).

\section{Conclusions}

A historical timber truss has been reassembled, analysed and then tested in laboratory conditions. With a total load of $268 \mathrm{kN}$, the failure of the rafters was reached, plus some more damages in the other elements. The test has been recorded by a full set of LVDTs placed in the crucial positions. The truss has been later retrofitted with a system of post-tensioned steel cables, and retested under the new conditions. The maximum force borne was equal to $220 \mathrm{kN}$, which represent a recovery of the $82 \%$ of the original load-carrying capacity. The comparison between the displacements measured in both tests reveals a change in the structural behavior, as the activation of alternative resisting mechanisms, showing that the residual capacity of the truss has been used to resist the load.

\section{Acknowledgments}

The present work was made within a Master thesis of the Erasmus Mundus Advanced Masters course in Structural Analysis of Monuments and Historical Constructions. The authors acknowledge also the support and assistance of Augusto de Oliveira Ferreira e Companhia Lda (AOF).

\section{References}

[1] Gasparini D. A., da Porto F., 2003, Prestressing of $19^{\text {th }}$ century wood and iron truss bridges in the U.S., in Proceedings of the First International Congress on Construction History, Madrid: S. Huerta ed., pp. 978-986.

[2] Tampone G., 1996, Il restauro delle strutture di legno, Milano: Hoepli, pp. 321. 
[3] Paolini L., Messina C., Marradi A. M., 1989, Il restauro della copertura del teatro Chiabrera a Savona, in "Legno e restauro", a cura di G. Tampone, Firenze: Messaggerie toscane.

[4] EN 408:2003, Timber structures - Structural timber and glued laminated timber Determination of some physical and mechanical properties, European Committee for Standardization.

[5] LNEC, 1997, Madeira para construção - Ficha M2: pinho bravo para estruturas, Lisbon.

[6] Carballo J., Hermoso E., Fernandez-Golfin J. I., 2009. Mechanical properties of structural maritime pine sawn timber from Galicia (Pinus pinaster Ait. ssp. Atlantica), Madrid: Insituto Nacional de Investigacion y Tecnologia Agraria Y Alimentaria.

[7] Branco J. M. et al., 2015, FP1101 and RILEM TC245 RTE Training school on assessment and reinforcement of timber elements and structures, Lisbon: (in press) HEaRT.

[8] Jurina L., Bassoli A., 2011, Il recupero della copertura lignea della Chiesa di San Carpoforo a Milano, in Ingegneri, n. 5, y. 3, Milano: Maggioli editore., pp. 10-11. 